
The final diagnosis was chronic intussusception from chronic constipa-
tion, with secondary purpura. The patient eventually made a complete recovery.

There does not appear to be any necessity to assume the existence of an intussusception in either of these cases. In Dr. Still's case there was an intussusception, the necropsy showing a recent invagination, but the passage of blood from the bowel had been going on at intervals for eight months. Pure blood in large quantity is not usually passed in cases of intussusception, and far less in the chronic form where the circulation in the invaginated portion is not seriously interfered with. Consequently, from the history of severe melæna in Dr. Still's case it may be suggested that the primary trouble was intestinal effusion of blood, and that as the result of this intussusception occurred shortly before death, as has happened in other recorded cases.

This form of intestinal hæmorrhage may simulate certain affections of the colon such as mucous colitis, acute ileocolitis, and ulcerative colitis. In fatal cases there may be found extensive ulceration of the colon due to the sloughing of the mucous membrane at the hæmorrhagic areas, which ara often diffused widely over the bowel.

CASE 22.-A female child, aged three years, was seized with sudden pain in the left side of the abdomen and passed two motions containing blood and mucus. The temperature rose to $103.4^{\circ} \mathrm{F}$. There were frequency of micturition and tenderness over the descending colon. During the next 24 hours she passed on five occasions a large quantity of blood and mucus, and the attacks of pain were sharp and intermittent The temperature then fell to normal. On the third day there was a good deal of mucus passed, with only a trace of blood, and facal matter was present. Some thickening was felt in the left inguinal region but nothing abnormal on rectal examination. The symptoms rapidly passed off and there was no recurrence or evidence of hæmorrhage elsewhere.

This case may be variously interpreted, but from the attacks of pain I was led to believe that hæmorrhage had taken place into the bowel wall. I have seen similar sym. ptoms in a young woman who was said to suffer from mucous colitis. In one of these attacks when she was under observation she passed large quantities of blood and mucus by the bowel and suffered from intermittent and colicky pain in the region of the colon. At other times she suffered from attacks of angio-neurotic œdema, the whole face becoming swollen and œdematous.

CASE 23 (Dr. Ashby's case).18-A boy, aged nine years, was suddenly seized with pain in the abdomen whilst at school, followed by the passage of blood and mucus by the bowel; the symptoms continued during the night. After admission next day he passed in the course of 24 hours 12 stools, consisting almost entirely of blood and mucus. Tenesmus and bloody stools continued, and large enemata brought away but a small quantity of fæcal matter. The abdomen was not dis tended or tender and nothing could be felt on palpation in the way of a tumour. It was resolved to open the abdomen in order to relieve an invagination of the bowel if present. This was done but only an invagination of the bowel if present. This was done but only an intensely congested colon was found. Death followed eight hours later. At the necropsy the stomach and small intestines, to within 20 inches of the cxcum, were found normal ; the last foot or two of ileum was found congested, with patches of thin memabranous exudation. The mucous membrane of the colon, sigmoid flexure, and rectum was intensely injected, the changes in the lowest parts being most marked, and the rectum being hæmorrhagic. There was no ulceration. (This "case was recorded by the late Dr. Ashby in his standard work as one of "acute ileo-colitis," but he wrote me that he had come to the conclu severity.)

Ulcerative colitis is not a common affection in early life and some of the recorded cases seem rather to fall into the category of the affection we are considering. The postmortem evidence is by no means conclusive, for it may not settle the question as to whether the ulceration was primary and the hæmorrhage secondary or vice vers $\hat{a}$. In cases of Henoch's purpura I have seen definite ulceration of the colon which was clearly secondary to hæmorrhage into, and sloughing of, the mucous membrane. The presence of other hæmorrhages in the bowel wall is always suggestive of a primary hæmorrhagic affection and secondary ulceration. A diagnosis of acute dysentery is also sometimes made when the clinical course of the disease can be fully explained by a condition of extensive hæmorrhagic effusion into the wall and the lumen of the bowel.

It is difficult to bring forward any evidence from the textbooks of the gravity and importance of these gastro-intestinal crises from hæmorrbage because the condition is generally ignored and any examples are usually to be found classed under some other disorder. Without adding anything fresh I have tried to show by collecting a number of cases that the condition is one of considerable importance, and that there

18 Ashby and Wright: Diseases of Children, p. 102. are various problems connected with it about which we require more information before any dogmatic statements can be made.

Wimpole-street, W.

\section{A CASE OF ACUTE MASTOIDITIS, WITH LATERAL SINUS SUPPURATION AND CEREBELLAR ABSCESS AS COMPLICA- TIONS OF THE OPERATION FOR THE REMOVAL OF TONSILS AND ADENOIDS.}

By L. A. PARRY, B.S. Lond., F.R.C.S. ENG.,

ASSISTANT SURGEON, ROYAL ALEXANDRA HOSPITAL FOR SICK CHILDREN, BRIGHTON.

A CHILD, aged seven years, had an operation performed for the removal of tonsils and adenoids on Dec. 28th. She was kept in bed for five days, and was then looked upon as convalescent. Nine days later she was admitted to the hospital with the history that she had had ear trouble in both ears for four days. On admission the temperature was $100 \cdot 6^{\circ} \mathrm{F}$., pus was discharging freely from both ears, and on the right side there was a superficial mastoid abscess which was opened at once. The mastoid antrum was at the same time cleared out and found to be full of pus. No improvement resulted, and as the child was very ill, the temperature having risen to $104 \cdot 2^{\circ}$, the wound was opened up 48 hours later. Pus was seen to be welling into the cleaned out mastoid antrum from behind, so the lateral sinus was exposed and the groove was found to be full of pus. The internal jugular vein was not considered at this time to be thrombosed. The child did not improve. She was desperately ill and had pyæmic symptoms. The tem. perature was $104 \cdot 8^{\circ}$, and there was a little diarrhoea. On Jan. 15th, two days after the second operation, the internal jugular vein in the neck was divided between two ligatures; it was quite patent. The old wound was opened up and the sigmoid groove exposed more freely both in a downward and backward direction. The temperature remained high, up to $105^{\circ}$, for three days, and then gradually fell to normal. Convalescence was slow; it was a month before the child really showed much vitality. Early in February paralysis of the facial nerve of the side operated on became suddenly. marked, but this disappeared without any special treatment, and the child was in March perfectly well. She was sent in very good condition to a convalescent home, and after being there about four weeks was readmitted to the hospital on April 29th because she had become drowsy, was sick, and had had a convulsion. On that day she was dull and apathetic, had a subnormal temperature, and a slow pulse. She was sick several times and had a few slight general convulsions soon after admission. As the symptoms of cerebral abscess were quite clear she was trephined at once over the cerebellum. This spot was selected in preference to the temporo-sphenoidal lobe as the lateral sinus groove had been diseased previously. At the first puncture of the cerebellum pus flowed freely by the side of the sinus forceps, a tube was put in, and in a few hours the child was sitting up in bed, quite lively. Drainage was difficult, the tube having to be readjusted and the track dilated on two or three occasions, owing to the reappearance of symptoms of cerebral pressure. Later a discharge of cerebro-spinal fluid was seen, slight symptoms of meningitis developed, and the child died comatose on June 1st, five months from the commencement of her illness.

Necropsy. - The right lobe of the cerebellum was converted into a large abscess cavity; there was a communication between it and the lateral ventricle of the same side, which, as well as the left ventricle, was full of pus. I think if it had not been for the last unfortunate complication (the com. munication of the abscess cavity with the ventricles) the child would have lived. I do not see how such a misfortune could have been avoided, nor what could have been done for it when it had occurred.

There are one or two points of interest in this case. First, acute mastoiditis and its complications is fortunately an exceedingly rare result of the operation for the removal of tonsils and adenoids. Neither of my two senior colleagues nor 
myself, in a very extensive experience of this operation, has ever seen it before. Otitis in its various forms is not uncommon, especially in those children who have had previous ear trouble (in this case no history of any ear trouble could be obtained). It is, I think, generally due to sepsis spreading up the Eustachian tubes from the raw surface left round the orifices by the scraping. I am sure I have seen this complication less frequently since I have adopted the plan of scraping only strictly in the middle line and leaving the few scraps around the orifices of the tubes alone. Another important factor in the avoidance of subsequent ear trouble is the after-treatment, $a$ week in bed in a warm room being the most essential point. Secondly, it brings home closely to one the fact that this operation is not always the trifle it is sometimes thought to be. Many complications may follow it-e.g., ear trouble, suppuration in the lymph glands of the neck, hæmorrhage which may even be fatal, and so on. I think we should never tell the parents that the operation is a very minor one.

I am largely indebted to my colleagues, Mr. G. Morgan and Mr. H. H. Taylor, for advice and assistance in connexion with this case.

Brighton.

\section{ORAL SEPSIS IN ITS CONNEXION WITH THROAT DISEASE. ${ }^{1}$}

BY GEORGE IRVINE STEWART, M.A., B.Sc., M.B., C.M. ABERD., F.R.C.S. ENG.,

COUNTY SCHOOL MEDICAL OFFICER, EAST SUFFOLK; LATE CHIEF ASSISTANT, THROAT DEPARTMENT, ST. THOMAS'S HOSPITAL.

\section{The Signs of Oral Sepsis.}

THERE are many more than are to be found in text-books. All of them can be categorised under the signs of inflammation of mucous membranes-redness, swelling, heat, pain, increased secretion, and loss of function. A peritonsillar abscess is the best example of an intense oral sepsis.

Redness. -This varies in intensity and can be general or local ; locally it is most evident opposite a focus such as a septic tooth. In slight cases it is evident as a red line parallel to, but separated by one-sixteenth of an inch from, the border of the gums. As long as this red line is present there is oral sepsis. It is most persistent on the gums bordering the lower molars, and particularly the lower incisors. A characteristic reddening from oral sepsis is to be seen on the soft palate, as a red band half an inch broad commencing on the anterior pillar and arching round towards the centre of the soft palate, but just stopping short of the uvula. The remainder of the soft palate may be quite pale and the red band shows up very distinctly.

Swelling. - This is evident in most cases. It involves all the mucous membranes-of the gums; of the cheeks, which have the teeth plotted out in the odematous swelling; of the tongue, which is similarly marked by the teeth; and of the lips. The swelling of the lips is most marked in infants, leading to a great protrusion and eversion of the lower lip.

Heat and pain are not extreme, but in some cases the breath appears hotter than normal, and discomfort causes the speech to be slovenly.

Increased secretion is evidenced in slight cases by the breaking of bubbles between the back part of the tongue and the soft palate when the mouth is opened. In the worst cases-e.g., in peritonsillar abscess-the dribbling is excessive. Dribbling is also well seen in the "teething" of infants, which is neither more nor less than a fairly intense stomatitis, and is most evident in bottle-fed babies in whom decomposition of milk is more likely to occur.

Loss of funotion.-Of all the signs of oral sepsis this is the most marked and has been the least recognised in its significance and its detrimental effects. It is characterised by diminution or loss of function of all the muscles of the oropharynx-viz., those of the pharynx, palate, tongue, cheeks, and lips. The buccal, oral, and lingual muscles are used for forwarding the food particles to the gullet, for keeping the mouth clear of food, for cleansing the mouth and teeth, and with the pharynx for articulation of speech. The teeth owe a great part of their cleanliness to proper tonicity of those muscles, and the moment their function is diminished by oral sepsis there is an increase of deposited muco-pus and an increase of oral sepsis; that is to say, a true vicious circle is started. The teeth that receive the least cleaning naturally can be readily identified-viz., the lower incisors and the lower molars, precisely the ones that show the red line, the sign of oral sepsis, longest.

The speech in oral sepsis, on account of the lack of tone in the muscles and from the discomfort caused by the swelling of the mucous membranes, becomes slovenly, partially guttural in character, the back part of the tongue being used in preference. It is so characteristic that perhaps the term "circumvallate" speech might be coined for this, as it is in the region of the circumvallate papillæ that the speech is articulated. An extreme case of this sort in a child where the speech was almost unintelligible was cured by proper use of the toothbrush (and the exercises in articulation by the teacher which before had been tried in vain).

The result of this loss of function of the muscles, to which I should wish to call most particular attention, is the dropping of the lower jaw and of the lower lip, which becomes thereby everted. The well-known open-mouth vacant expression usually attributed to adenoids and other nasal obstruction is really a characteristic of oral sepsis, which itself may be set up by nasal obstruction. The socalled "adenoid facies" is really that of oral sepsis, however induced. It is well seen in "teething " infants.

\section{The Effect of Oral Sepsis on the Throat Generally and Particularly on the Tonsils.}

My attention was first drawn to this by the need of finding other causes for laryngitis than "hysterical aphonia" and "nasal laryngitis." In throat hospitals the practice prevailed of at once depressing the tongue with the spatula, thereby concealing the teeth from view, without previously examining the state of the mouth. The practice of first drawing the cheeks aside to examine the state of the teeth is getting more and more universal. The following cases helped to emphasise the importance of oral sepsis in throat work.

CAsE 1. - A male, aged 40 years, diagnosed by a wellknown laryngologist as having tuberculous laryngitis. The cords were reddened and there was much muco-pus on the slightly swollen arytenoids. Quiescent tuberculosis was present at the right apex. He had a complete upper tooth plate lying on a row of septic stumps, each surrounded by florid granulations. Removal of the stumps on my advice cured the laryngitis in a month.

CAsE 2.-A male, aged 19 years. His voice began to break four years ago. For the past two years he had been under treatment at a throat hospital for "squeaky" voice. The cords were reddened; approximation was incomplete. Removal of one stump and careful brushing of the teeth produced in six weeks such an alteration in the voice that his family and himself were continuously laughing about it. He had now a clear bass voice.

OASE 3. - The patient, a male medical practitioner, used to suffer from four or five severe colds every winter. He got severe septic stomatitis caused by sucking a post-mortem wound of the finger. Great attention has since been paid to cleansing the teeth. He now has one "cold" in two years on the average.

Seven elementary school teachers frequently off duty for loss of voice, quinsies, and sore-throat; since having the teeth attended to they have rarely any trouble.

Peritonsillar abscess.-Of 49 cases of this condition 47 had an extremely septic lower molar on the same side. One case (bilateral) had septic molars on both sides. The pus from those abscesses has the same characteristic odour as that from a dental antrum. The oral sepsis in those cases is extreme and is usually regarded as secondary ; it is probably primary.

Unilateral enlargement of the tonsil. - of 231 cases (in children of school age) of unilateral enlargement of the tonsil 135 had dental caries, mostly of lower molars, and oral sepsis on the side of the enlarged tonsil ; 67 had dental caries and oral sepsis on both sides; 16 had no oral sepsis at all ; and 15 had dental caries and oral sepis on the opposite side. I have never seen a case of unilateral inflammatory enlargement of the tonsil in an infant, in whom, of course, the oral sepsis is always bilateral. I believe that the organisms round septic teeth travel directly backwards along the sulci on either side of the lower jaw, and, meeting with 